УДК 343.9:340.115

\author{
В. Н.Дрёмин
}

\title{
МЕТОДОЛОГИЧЕСКИЕ ВОПРОСЫ ФОРМИРОВАНИЯ ИНСТИТУЦИОНАЛЬНОЙ КРИМИНОЛОГИИ
}

Одним из механизмов криминализации общества является широкое распространение особой разновидности массового социального поведения - криминальных практик, которые деформируют базовые социальные институты, а те, в свою очередь, создают условия для криминализации личности и общества. Криминальные практики, выступая необходимым условием возникновения и функционирования особых по своим свойствам социальных институтов, могут и влиять на институциональную структуру общества. Эти и иные смежные проблемы формируют представление о частной криминологической теории, которую мы называем «институциональная криминология». Одной из задач институциональной криминологии является изучение преступности как относительно самостоятельной разновидности социальной практики (криминальной практики), тесно связанной с иными видами активности человека в различных социальных сферах. Предметом криминологического изучения в таком разрезе должна стать институционализация отдельных видов криминальных практик (организованной преступности, коррупции, теневой экономики, налоговых правонарушений и др.) и институциональное перерождение общества вследствие его криминализации (криминализация социальных институтов) [3].

В данной статье предпринята попытка осмысления преступности и её криминологического изучения с позиций институциональной методологии.

Проблема институционализации криминальных практик в криминологической литературе в Украине на монографическом уровне начала изучаться только в последние годы, хотя актуальность разработки теоретической концепции, в которой были бы рассмотрены вопросы криминализации современного общества и расширенного воспроизводства преступ-

(C) Дрёмин В.Н., 2013 
ности, не вызывала сомнений. Вместе с тем следует отметить, что в трудах некоторых известных украинских ученых говорится о необходимости анализа преступности с позиций институционализма. О криминологических аспектах институциональной теории преступности в рамках социологических исследований писали С. А. Гриценко и И. П. Рущенко, в русле изучения экономической преступности - В. М. Попович, в контексте виктимологичних проблем - В.О.Туляков, в общетеоретическом аспекте - автор этих строк.

В России методологию институционального анализа преступности применяют Н. Б. Бараева, С. Ю. Барсукова, Л. В. Гевелинг, Я. И. Гилинский, С. П. Глинкина, В. М. Есипов, В. О. Исправников, В. В. Колесников, И. М. Клямкин, Л. Я. Косалс, Ю. В. Латов, А. М. Олейник, В. В. Радаев, Р. В. Рывкина, Г. А. Сатаров, Л. М. Тимофеев и другие известные ученые. Весомым вкладом в развитие институционального подхода к изучению преступности стали докторская диссертация Н. Б. Бараевой «Организованная преступность как социальный институт» (2002); исследования теневой экономики, основанные на трактовке ее как института (комплекса институтов), осуществленные Ю. В. Латовым; труды А. М. Олейника в рамках изучения тюремной субкультуры и ее влияния на общество.

Институционализм как методологическая теория не является новейшей концепцией. Еще Э. Дюркгеймом и Р. Мертоном было убедительно доказано, что анализ девиантного поведения предполагает изучение социальных институтов, процесса «институционализации нарушений институциональных правил». Формирование институционального направления в правоведении связано с именами М. Ориу, Л. Дюги, Г. Гурвича, П. Сорокина, Ж. Ренара.

Заметное место в западной науке занимает институциональный подход в изучении преступности в рамках теории «экономики преступлений и наказаний» (Т. Шеллинг, Г. Беккер). Интерес к проблемам преступности в контексте институциональной теории проявляли лауреаты Нобелевской премии М. Фридмен, Д. Стиглер, Дж. Бьюкенен. Лидером неоинституционально-эволюционной теории справедливо называют американского ученого, лауреата Нобелевской премии Д. Норта, который создал широкую концепцию институтов и институциональной динамики. Для развития институциональной теории в криминологических целях важно подчеркнуть, что в основе институционализма Д. Норта находится теория человеческого поведения.

Как уже подчеркивалось, особое внимание функциональной нагрузке институтов уделял Э. Дюркгейм. Он считал главной функцией социальных институтов обеспечение целостности общества. Дюркгейм придерживался идеи о позитивности общественных институтов, которые являются важнейшим средством самореализации человека [4, с. 19; 5]. Социальные институты он образно определял как «фабрики воспроизводства» социальных отношений и связей, считая институтами опреде- 
ленные типы отношений между людьми, которые постоянно востребованы обществом и поэтому возрождаются вновь и вновь [4, с. 184].

Общеизвестно широко цитируемое учеными суждение Е. Гиденса о том, что социальные институты «цементируют общественную жизнь», «обеспечивают общие соглашения, выработанные людьми в общении друг с другом и при содействии которых достигается преемственность поколений» [6, с. 344].

Бесспорно, большая часть преступлений, которые рассматриваются нами как разновидность социальных противоправных практик (криминальные практики), не соответствует таким критериям. Данный вопрос криминологами изучен недостаточно, что заставляет обратиться к работам социологов, разрабатывающих концепцию институционализации неправовых практик. Значительный вклад в формирование концептуальных основ институционализации неправовых практик и изучение этой проблемы внесли российский академик Т.И. Заславская и ее коллеги [7-12]. Важно обратить внимание на то, что, по мнению Т. Н. Заславской и М. А. Шабановой, институционализируются преимущественно те социальные практики, которые отличаются либо большей значимостью и массовостью, либо устойчивостью и традиционностью. Именно такие практики составляют устойчивое ядро жизнедеятельности данного общества. Одновременно те, которые возникли недавно, менее значимые, сравнительно редкие, ненормативные или противозаконные практики представляют обычно ее периферию. В здоровых обществах и нормальных условиях государственные законы и нормы воспринимаются большинством граждан как справедливые и поэтому реализуются в массовых социальных практиках. В обществах, которые трансформируются, дело совсем иное, подчеркивают авторы. Длительное ослабление институциональных систем нередко приводит к тому, что отклонение реальных практик от правовых норм стабилизируется, в результате чего они приобретают стойкий неправовой характер. Между тем институционализация неправовых практик означает перерождение (или мутацию) институтов [11].

Сформулированные социологами положения находят подтверждение в реальной жизни: деинституционализация государственных институтов происходит за счет проникновения криминальных практик в их деятельность. Мнение социологов важно для понимания системности процессов криминализации общества и институционализации отдельных видов криминальных практик.

Мы считаем, что многомиллионная армия бывших и действующих делинквентов в процессе своей «практической» деятельности вполне может повлиять на сущностное бытие того или иного социального института. Миллионы людей, побывавших в местах лишения свободы, и действующих преступников являются носителями особой идеологии, основанной на специфических социальных ценностях и установках. Тесная взаимосвязь противоправных, в том числе криминальных, 
и правомерных социальных практик отражает наше представление о преступности как жизнедеятельности людей в условиях институционализированных «разрешений»и запретов. В исследованиях других авторов мы находим подтверждение такой позиции. Е. Н. Митракова вполне обоснованно утверждает, что развитие неформального пространства является закономерным явлением начального этапа институциональной и общественной трансформации как самоорганизующегося механизма налаживания общественного взаимодействия в различных сферах жизни общества. Неформальные отношения обеспечивают оперативность и гибкость в решении индивидуальных и групповых интересов и потребностей; создают неформальные, действенные механизмы социального влияния, давления и защиты своих прав и законных интересов, которые подменяют нерезультативное функционирование официальных институтов публично-правового взаимодействия. По ее мнению, неформальные практики - это не пассивная социальная субстанция, а вполне активное и самодостаточное социальное явление, которое стремится заполнить собой пробелы и коллизии в нормативноправовом регулировании общественных и этнополитических процессов, обусловливающих конфликтогенное взаимодействие официального и неформального пространств [13, с. 19].

Сравнительно-правовые исследования показывают, что практически в каждой правовой системе существует концепция соотношения формального и неформального права (официального и теневого правотворчества). В рамках этой концепции существует относительно четкое понимание сущности неформального права, системы критериев, по которым те или иные теневые отношения оцениваются обществом как положительные или отрицательные, а также сформулирована концепция институционализации неформальных отношений и соответствующий процессуальный механизм, переводящий положительные правила и модели отношений из неофициальной (теневой) сферы в публично-правовые модели взаимодействия [13, с. 20]. Результаты исследований, проведенных в Научно-учебном центре по изучению нелегальной экономической деятельности (Российский государственный гуманитарный университет), показали, что формальное и неформальное, легальное и нелегальное составляют единую систему, охватывающую не только хозяйственную деятельность, но и другие сферы общественного бытия - политику, административную, правоохранительную и правоприменительную деятельность, сферу социальных гарантий и т.п. [14].

Особую методологическую значимость для криминологов имеет концепция институционализации, разработанная Т. Лукманом и П. Бергером. На наш взгляд, основные положения этой концепции могут быть взяты за основу институциональной теории криминализации общества. Они дают важный инструментарий для поиска ответа на вопрос, каким образом криминальные практики, типизируясь, приобретают качества социальных институтов, а те, в свою очередь, воспроизводят следующие 
криминальные практики. Излагая этот материал и ссылаясь на труды П. Бергера и Т. Лукмана, воспользуемся исследованием Е. А. Островской-младшей, которая глубоко изучила научные взгляды указанных ученых, представляющие несомненный интерес для криминологов [15].

Институционализацию общества Т. Лукман и П. Бергер связывают, прежде всего, с практической деятельностью людей, которая имеет предметный характер. Ученые воспринимают общество как объективную реальность, продукт опредмеченной человеческой деятельности, объективированной исторически. Объективированная социальная реальность институциональна и имеет принудительную силу над индивидом. В своей трактовке объективной реальности общества как типизированной деятельности Т. Лукман и П. Бергер придерживаются немецкой традиции интерпретации институционального генезиса общества. Общество определяется ими как социальная реальность, которую конструируют люди в процессе их повседневного взаимодействия. Дефиниции понятий «институт»и «институционализация» Т. Лукман и П. Бергер связывают с анализом объективной реальности общества [15]. Общество в их интерпретации выступает как совокупный запас знаний, который конструируется индивидами в процессе взаимодействия и закрепляется социально в виде институтов [16, с. 92-101].

Объективность институтов, согласно Т. Лукману и П. Бергеру, порождается их воспроизводством в поколениях, их историчностью. «Наиболее общий ответ на этот вопрос таков: социальный порядок - это человеческий продукт или, точнее, непрерывное человеческое производство. Он создается человеком в процессе постоянной экстернализации. Социальный порядок в своих эмпирических проявлениях не является биологически данным или образованным из любых биологических данных... Социальный порядок не является частью «природы вещей» и не возникает по «законам природы». Он существует лишь как продукт человеческой деятельности. И в своем генезисе (социальный порядок как результат прошлой человеческой деятельности), и в своем настоящем (социальный порядок существует, поскольку человек продолжает его создавать в своей деятельности) - это человеческий продукт... Чтобы понять причины (отличные от тех, основу которых составляют биологические константы) возникновения, поддержания и передачи социального порядка, следует проанализировать то, что содержится в теории институционализации», - пишут Т. Лукман и П. Бергер [16, с. 89-90].

В этой связи концепция институционализации должна быть инструментом анализа происхождения социального порядка, форм его поддержки и воспроизведения. Институционализация, по Лукману и Бергеру - динамический процесс возникновения, установления и передачи социального порядка. В этом процессе они выделяют три последовательных этапа - типизацию, объективацию и легитимацию [15, c. 100-102]. 
Первый этап институционализации - типизация. Необходимым антропологическим условием типизации является габитуализация деятельности. «Любая человеческая деятельность подвергается габитуализации (т. е. «опривычиванию»). Любое действие, часто повторяющееся, становится образцом, впоследствии оно может быть осознано его исполнителем как образец. Кроме того, габитуализация означает, что действие может быть снова совершено в будущем тем же образом и с тем же практическим усилием [16, с. 90]. Понятие «габитуализация»является производным от понятия «габитус» (от лат. Habitus - свойство, состояние, положение). Этот термин используется современными криминалистами и судебными медиками, однако в криминологии до последнего времени не применялся [17]. Вместе с тем механизм институционализации криминальных практик сложно описать без использования теории габитуализации.

Концептуализация этого понятия связана с именем П. Бурдье, в теории которого оно является центральной категорией. В книге «Практический смысл» П. Бурдье развивает собственную версию социальной теории практик и соответствующий понятийный аппарат. Особое место в книге отведено понятию «габитус». Габитус определяется П. Бурдье как совокупность практических дорефлективных и доинтенциональных склонностей социального актора, которые функционируют как «структурирующая структура», т. е. как принципы, порождающие и организующие практики и представления, объективно приспособленные для достижения определенных результатов, но не предполагающие сознательной нацеленности на эти результаты [18]. Габитус предстает как некая активная сила, которая представляет собой инкорпорированые социальные структуры и социальные траектории индивидов и предопределяет все возможные для индивида практики и представления. Габитус, таким образом, является тем, что «генерирует социальные практики индивидов, причем чаще тайком от них самих» [19]. Детерминации, связанные с особым классом условий существования, производят габитус - системы устойчивых и переносных диспозиций, структурированные структуры. Габитус производит практики индивидуальные и коллективные, дает гарантию тождества и постоянства практик во времени [20]. Габитус, по П. Бурдье, функционирует как порождающий механизм, способный спонтанно производить в большинстве социальных ситуаций практики, выражающие один общий принцип. Иными словами, габитус - это способность свободно реализовывать на практике усвоенные схемы восприятия, мысли, коммуникации, действия. Вместе с тем габитус устанавливает и жесткие рамки ограничения этой производительной способности: с помощью изначально заданных принуждений и ограничений [19].

Рассматривая механизм репродуцирования институциональных моделей и интерпретируя их в отношении тюремной системы, к концепции габитуса обращается А. Н. Олейник $[21$, с. 7,37$]$. В другой работе, которую цитирует А. Н. Олейник, говорится, что «габитус предполагает тен- 
денцию к бесконечному воспроизведению мыслей, выражений, действий, способов восприятия, формирование которых всегда исторически и социально предопределено» [22, р. 116; 21, с. 37].

По Т. Лукману и П. Бергеру, наиболее важная часть габитуализации человеческой деятельности связана с процессом институционализации. Последняя проявляется везде, где осуществляется взаимная типизация принятых действий деятелями разного рода. Типизации принятых действий, составляющих институты, всегда разделяются; они доступны для понимания всех членов определенной социальной группы, и сами институты типизируют и индивидуальных деятелей, и индивидуальные действия. Истоки любого институционального порядка находятся в типизации совершаемых действий, как наших собственных, так и других людей [16, с. 90-92, 122].

Второй этап институционализации, согласно данной концепции, объективация, т. е. процесс, посредством которого продукты человеческой деятельности приобретают характер объективности. Т. Лукман и П. Бергер считают, что институциональный мир - как и любой отдельный институт - это объективированная человеческая деятельность. Институты предполагают историчность и контроль. Институты контролируют человеческое поведение, устанавливая его образцы, которые придают поведению одно из многих, теоретически возможных направлений. Ученые подчеркивают, что этот контролирующий характер присущ институционализации как таковой, независимо от того и еще до того, как были созданы какие-либо механизмы санкций, поддерживающих институт. Институты оказываются для индивида внешними, такими, которые сохраняют свою реальность независимо от того, нравится ли она ему. Он не может избавиться от них. Они имеют над ним принудительную власть и сами по себе, благодаря силе своей фактичности, и благодаря механизмам контроля, которыми обычно располагают наиболее важные институты [16, с. 101-102, 145].

Третий этап институционализации - легитимация. По Т. Лукману и П. Бергеру, легитимации - это когнитивные и нормативные интерпретации институционального порядка, воспринимаемые в процессе социализации. «Институты должны утверждать свою власть над индивидом (что они и делают), независимо от тех субъективных значений, которые он может предоставлять каждой конкретной ситуации, - пишут Т. Лукман и П. Бергер. - Чем больше поведение институционализировано, тем более оно становится предсказуемо, а значит, и контролируемо» [16, с. 104-105]. Т. Лукман и П. Бергер подчеркивают, что институционализация не является необратимым процессом: из-за многих исторических причин границы институционализированных действий могут уменьшаться; в отдельных сферах социальной жизни может проявляться деинституционализация [16, с. 134-135].

Во многих исследованиях отмечается, что возросла толерантность к девиантному поведению. Утверждается, что «возник сектор анархическо- 
го порядка, включающий не только экономическую самодеятельность, но и криминал» [23]. «Здесь мы сталкиваемся с феноменами криминогенной системы - особого общественного организма, который, по словам Д. Игнатиуса, делает преступников из людей (точнее, исполнителей совершенно иных социальных ролей), которые в других условиях могли бы вести честный образ жизни», - замечает Л. В. Гевелинг [24]. Автор полагает, что приспособление к социальной реальности является важным звеном в механизме криминализации человеческого поведения. В связи с этим необходимо выяснить проблему формирования адаптивных криминальных практик. Если рассматривать проблему институционализации преступности сквозь призму адаптации населения к социальным изменениям, нужно согласиться с тем, что «рациональное поведение» может воспроизводить криминальные практики [24]. Криминологи утверждают, что криминальные формы выживания стали осваиваться вполне обычными людьми; возник своеобразный частный сектор правонигилистического порядка, допускающий криминальную деятельность [25].

Социально-экономические и социально-психологические факторы воспроизводства криминальных практик позволяют сделать вывод о значительной зависимости поведения людей от социальной среды обитания и, в каждом конкретном случае, - от комплекса социальных институтов, которые формируют его образ жизни. Человек формирует свою жизненную среду, но при этом остается объектом, а зачастую и «жертвой»её влияния. Роль конкретных социальных механизмов, определяющих содержание и направленность социальных практик, в воспроизводстве и инстуционализации преступности явно недооценивается, иначе политика государства в сфере противодействия преступности не ориентировалась бы исключительно на репрессивные уголовно-правовые меры.

Практический аспект влияния преступности заключается в том, что преступления связаны с посягательством на определенные социальные отношения, интересы, ценности; большая часть преступных деяний совершаются умышленно, а лица, их совершившие, дают аргументированные объяснения мотивам и целям своих действий. Некоторые преступные деяния проявляют себя в виде действия, бездействия, операции, поступка, при этом социокриминологический анализ таких деяний позволяет увидеть тесную предметную связь преступлений-действий, преступлений-операций, преступлений-поступков с иной социально значимой активностью человека, что и позволяет говорить о деятельностной взаимообусловленности преступного поведения.

Важными в этом отношении являются наблюдения А. И. Долговой: «Уже в начале девяностых годов стало очевидным, что реформирование российского общества сопровождалось широкой криминализацией населения, разных сфер общественной жизни и структур власти. В преступную деятельность вовлекалось все большее число граждан, и она становилась для одних основным способом обеспечения высокого социального и материального статуса в условиях обвального перехода к рынку, 
для других - средством выживания в этих условиях, защиты своих прав и законных интересов, для третьих - выражением своеобразного социального протеста. Одновременно продолжала расширяться та часть преступности, которая производна от процессов крайней деморализации населения, психологии ничем не ограниченного эгоизма, правового нигилизма и цинизма» [26].

Рассмотренные вопросы не исчерпывают проблему. Теоретические и практические аспекты механизма институционализации криминальных практик в криминологической литературе требуют глубокого всестороннего изучения. Как уже отмечалось, в большей степени этот вопрос исследован российскими учеными относительно неправовых практик. Несмотря на совпадение целого ряда признаков и свойств, было бы ошибочно отождествлять процессы и механизмы институционализации неправовых и криминальных практик. Несомненна взаимосвязь этих видов социальных практик, но и бесспорна особая социальная и психологическая природа преступности. Относительно многих массовых неправовых практик можно отметить, что они предстают в социальном измерении как разновидность социальных институтов. При этом мы, вслед за социологами, замечаем, что речь идет не о легальных общепризнанных социальных институтах, а о теневых, которые во многих случаях подменяют официальные институты. Однако далеко не все криминальные практики могут иметь свойства и признаки, дающие основание говорить о них, как об институционализированом социальном явлении. Большая часть криминальных практик не соответствует критериям даже теневого социального института, так как выполняет явно деструктивные, разрушительные функции. В этой связи нельзя согласиться с мнением, что преступность сегодня выступает как всеобъемлющий социальный институт. Такие разнородные преступления (криминальные практики), как убийства, разбои, изнасилования, террористические акты и т.д., с одной стороны, и коррупция, налоговые, служебные, экологические преступления, с другой, не могут сформироваться в единый социальный институт. В этом случае можно говорить лишь об институционализации отдельных криминальных практик. С этой точки зрения мы выделяем криминальные практики, которые могут быть институционализированы и выполнять функции социального института (например, теневая экономика, организованная преступность, коррупционное поведение), и преступления, которые ни при каких условиях не могут быть основой институционализации криминальных практик.

Преступность по своим качественным и количественным характеристикам, территориальной распространенности, социально-демографическим характеристикам лиц, в неё вовлеченных, представляет устойчивое социальное явление, которое развивается в соответствии с логикой развития общества в целом. Противоречия и несоответствия в институциональной системе реформированного общества, выступая важным источником формирования противоправных практик, постепенно втяги- 
вают в свою орбиту криминальные практики, превращая их в элемент институциональной системы общества. Преступность не просто вплетена в современные трансформационные отношения: идет активный процесс институционализации отдельных видов криминальных практик, то есть превращение преступности в устойчивый социальный феномен, который постоянно воспроизводится и, интегрируясь в формируемую систему общественных отношений, становится нормой (привычным образцом) поведения.

Распространенность криминальных практик в повседневной жизни приводит не только к привыканию и адаптации населения к преступности, но и формирует особое морально-правовое состояние общества, в котором соблюдение правовых предписаний может считаться «аномальным» явлением, а умение обойти закон - жизненным правилом.

Анализ поднятых в этой статье проблем ставит вопрос о развитии нового научного направления в криминологии - институциональной криминологии. Есть основания утверждать, что именно в рамках институциональной криминологии, на стыке таких наук как криминология, социология, политология, социальная психология, философия права возможны глубокое изучение конкретных механизмов институционализации преступного поведения и разработка адекватных социальных мер реагирования на эти процессы.

\section{Л и те р а т у р а}

1. Лунеев В. В. Преступность XX века. Мировые, региональные и российские тенденции / В. В. Лунеев; предисл. В. Н. Кузнецова. - М. : НОРМА, 1997.

2. Долгова А.И. Преступность, её организованность и криминальное общество / А. И. Долгова. - М. : Рос. криминол. ассоц., 2003. - 572 с.

3. Дремин В.Н. Преступность как социальная практика (институциональная теория криминализации общества) : монография / В. Н. Дремин. - О.: Феникс, 2009. 616 с.

4. Дюркгейм Э. О разделении общественного труда. Метод социологии / Э. Дюркгейм. - M. : Наука, 1990.

5. Дюркгейм Э. Педагогика и социология // Социология. Ее предмет, метод, предназначение / Э. Дюркгейм. - М., 1995. - С. 244-264.

6. Гидденс Э. Социология / Э. Гидденс. - М. : Эдиториал УРСС, 1999.

7. Заславская Т. И. О социальных факторах расхождения формально-правовых норм и реальных практик / Т. И. Заславская // Куда идет Россия? Формальные институты и реальные практики / под общ. ред. Т. И. Заславской. - М. : МВШСЭН, 2002. C. $11-21$.

8. Заславская Т. И. Социальные механизмы трансформации неправовых практик / Т. И. Заславская, М. А. Шабанова // Общественные науки и современность. 2001. - № 5. - C. 5-24.

9. Заславская Т. И. Неправовые трудовые практики и социальные трансформации в России / Т. И. Заславская, М. А. Шабанова // Социологические исследования. 2002. - № 6. - С. 3-17.

10. Заславская Т. И. О социальном механизме посткоммунистических преобразований в России / Т. И. Заславская // Социологические исследования. - 2002. - № 8. C. 3-16. 
11. Заславская Т. И. К проблеме институционализации неправовых социальных практик в России: сфера труда / Т. И. Заславская, М. А. Шабанова // Мир России. - 2002. - Т. 11, № 2. - С. 3-38.

12. Заславская Т. И. Социальная неравновесность переходного общества / Т. И. Заславская // Общественные науки и современность. - 1996. - № 4. - С. 5-14.

13. Митракова Е. Н. Институционализация неформальных политико-правовых практик в современной России как угроза национальной безопасности : автореф. дис. ... канд. юрид. наук / E. Н. Митракова. - Ростов н/Д, 2005.

14. Тимофеев Л. М. Научно-учебный Центр по изучению нелегальной экономической деятельности: итоги и перспективы, общие принципы и направления деятельности [Электронный ресурс] / Л. М. Тимофеев. - Режим доступа: http://www.rsuh.ru/ article.html?id=66; Тимофеев Л. М. Право собственности в СССР: коммунистическая доктрина и теневая реальность / Л. М. Тимофеев // Россия и современный мир. - 2000. - № 4. - С. 53-66.

15. Островская-младшая Е. А. Концепции институционализации в германской теоретической социологии второй половины XX века / E. А. Островская-младшая // Вестник РУДН. Серия Социология. - 2003. - № 1. - С. 96-113.

16. Бергер П. Социальное конструирование реальности. Трактат по социологии знания / П. Бергер, Т. Лукман. - М. : Медиум, 1995.

17. Дрёмин В.Н. Институционализация криминальных практик: криминологическая трактовка концепции «габитуса» Пьера Бурдье / B. Н. Дрёмин // Проблеми кримінального права, процесу та криміналістики: матеріали міжнародної науково-практичної конференції. - О. : Фенікс, 2009. - С. 64-67.

18. Бурдье П. Практический смысл : пер. с фр. / П. Бурдье; общ. ред., пер. и послесл. Н. А. Шматко. - СПб: Алетейя ; М. : Ин-т эксперим. социологии, 2001. - 562 с.

19. Шматко Н. А. Габитус в структуре социологической теории / Н. А. Шматко // Журнал социологии и социальной антропологии. - 1998. - Т. 1, № 2. - С. 59-69.

20. Бурдье П. Структура, габитус, практика / П. Бурдье // Журнал социологии и социальной антропологии. - 1998. - Т. 1, № 2. - С. 40-58.

21. Олейник А.Н. Тюремная субкультура в России: от повседневной жизни до государственной власти / А. Н. Олейник. - М. : ИНФРА-М, 2001. - 418 с.

22. Ensminger J. Making a Market. The Institutional Transformation of an AfricanSocletys / J. Ensmingcr. - Cambridge : Cambridge University Press, 1992. — P. 116 ; Цит по: Олейник А. Н. Тюремная субкультура в России: от повседневной жизни до государственной власти / А. Н. Олейник. - М. : ИНФРА-М, 2001. — С. 37.

23. Федотова В.Г. Криминализация России. Автохтомный капитализм как реакция на правый радикализм / В.Г. Федотова // Свободная мысль. Теоретический и политический журнал. - 2000. - № 2. - 2000. - С. 34-51.

24. Гевелинг Л.В. Деструктивные формы организации власти (клептократия, лутократия, плутократия в политической жизни африканской страны) : курс лекций / Л. В. Гевелинг // Текстовое (символьное) электронное издание. - М. : ИСАА при МГУ, 2004.

25. Кобцев Г. М. Современная государственная политика России по декриминализации общества : автореф. дис. ... канд. полит. наук: 23.00.02 / Г. М. Кобцев. — Ростов н/Д, 2007.

26. Долгова А. И. Развитие криминальной ситуации в России / А. И Долгова // Криминальная ситуация на рубеже веков в России / под ред. А. И. Долговой. - M., 1999. - C. 3.

27. Рущенко І̇. П. Соціологія злочинності : монографія / İ. П. Рущенко. - Х. : Вид-во Нац. ун-ту внутр. справ, 2001. 


\section{Анн н т а и я}

Дремин В.Н. Методологические вопросы формирования институциональной криминологии. - Статья.

В статье ставится вопрос о развитии нового научного направления в криминологии - институциональной криминологии. Есть основания утверждать, что именно в рамках институциональной криминологии, на стыке таких наук как криминология, философия права, социология, политология, социальная психология возможно глубокое изучение конкретных механизмов институционализации преступного поведения и разработка адекватных социальных мер реагирования на эти процессы.

Ключевые слова: преступление, криминальные практики, институционализация, институциональная криминология, социология.

\section{А н о т а ц і я}

Дрьомін В.М. Методологічні питання формування інституціональної кримінології. - Стаття.

У статті ставиться питання про розвиток нового наукового напрямку в кримінології - інституційної кримінології. Є підстави стверджувати, що саме в рамках інституціональної кримінології, на стику таких наук, як кримінологія, філософія права, соціологія, політологія, соціальна психологія можливе глибоке вивчення конкретних механізмів інституціоналізації злочинної поведінки та розробка адекватних соціальних заходів реагування на ці процеси.

Ключові слова: злочин, кримінальні практики, інституціоналізація, інституціональна кримінологія, соціологія.

\section{S u m m a r y}

Dryomin V.M. Methodological issues of institutional criminology formation. Article.

The article raises an issue on the development of a new academic direction in criminology - institutional criminology. There are grounds to assert that in-depth study of specific mechanisms of the criminal behavior institutionalization and elaboration of an adequate social response to these processes are more efficient in the framework of institutional criminology, placed in junction of criminology, philosophy of law, sociology, political science, social psychology.

Keywords: crime, criminal practices, institutionalization, institutional criminology, sociology. 